\title{
Multiple arterial anomalies in upper limb
}

\author{
Baral $P^{1}$, Vijayabhaskar $P^{2}$, Roy $S^{1}$, Kumar $S^{2}$, Ghimire $S^{3}$, Shrestha $U^{3}$ \\ ${ }^{1}$ Lecturer, ${ }^{2}$ Assistant Professor, Department of Anatomy, Manipal College of Medical Sciences, Pokhara, Nepal, \\ ${ }^{3}$ Post-graduate students, Department of Anatomy, B.P. Koirala Institute of Health Sciences, Dharan, Nepal.
}

\begin{abstract}
An isolated neurovascular variation is common but multiple vascular anomalies on same upper limb is a very rare case. We observed an unusual variations in right upper limb during routine dissection of a Nepali cadaver . The variations were observed in Axilla, Forearm and Palm. In axilla, first part of axillary artery did not give any branch, the second part of axillary artery gave off only two branches - (a) thoracoacromial artery and (b) a large common trunk which later gave off lateral thoracic, thoracodorsal, subscapular, posterior circumflex scapular and then continued as posterior circumflex humeral artery. The third part of axillary artery gave off only anterior circumflex humeral artery. In forearm, the ulnar artery runs downward superficial to flexor muscles. Here, radial artery gave off common interosseous artery. In palm radial artery did not give any contribution to superficial palmar arch which is solely formed by the continuation of ulnar artery. This type of anomalies are very rare and is not reported in Nepalese cadaver at all. These anomalies are described in detail and their clinical relevance is highlighted.
\end{abstract}

Key words : Axillary artery, Brachial artery, Radial artery, Ulnar artery, Palmar arch, Variations

$\mathrm{T}$ he arterial system of upper limb begins with the axillary artery, a continuation of subclavian artery from the outer border of first rib to the lower border of teres major. The artery is divisible into three parts by pectoralis minor muscle as it crosses the artery anteriorly: First part gives superior thoracic artery, second part gives thoracoacromial artery, lateral thoracic artery and third part gives subscapular artery, anterior and posterior circumflex humeral arteries. The axillary artery continues as brachial artery distal to the lower border of teres major. In arm the brachial artery gives profunda brachii, superior and inferior ulnar collateral and anterior and posterior descending branches. The artery ends by dividing into radial and ulnar arteries in cubital fossa (at the level of the neck of radius). Radial artery descends along the lateral side of the forearm and in the palm ends by anastomosing with the deep branch of ulnar artery to complete the deep palmar arch. It also contributes to the superficial palmar arch by giving superficial palmar branch at the distal part of forearm. Just distal to its origin the ulnar artery gives off common interosseous artery which divides into anterior and posterior interosseous arteries. It runs medially in the forearm deep to the superficial group of flexor muscles. In the palm, it forms superficial and deep palmar arches ${ }^{1}$.

Principal arteries of the upper limb show a wide range of variations that is of considerable interest to orthopaedic surgeons, plastic surgeons, radiologists and anatomists. In this paper, we are going to present a very rare anomaly regarding variation in arterial system of right upper limb which was observed during dissection of approximately 55 years old female cadaver in dissection hall of anatomy at BPKIHS, Dharan, Nepal for first year medical students.

\section{Case report}

The present arterial anomalies were found during routine dissection of the right upper limb of a 55 - year old Nepalese cadaver. The arterial anomalies were found at three sites - in the axilla, in the forearm and in the palm. The arterial pattern in left upper limb was normal.

\section{Variation in axilla}

In the axilla, branching pattern was abnormal. The first part of axillary artery did not give any branch. The superior thoracic artery was absent. The second part of artery gave two branches - (a) thoracoacromial artery that showed usual pattern. It emerged at the upper border of pectoralis minor muscle and was divided into four branches namely acromial, deltoid, clavicular and

\footnotetext{
Correspondence

Mr. P. Vijayabhaskar

Assistant Professor

Department of Anatomy

Manipal College of Medical Sciences

E-mail: pvijay_anat@yahoo.com
} 
pectoral, all followed usual course. (b) A large common trunk tat ran down and laterally. This common trunk gave following branches -

i) Lateral thoracic artery

ii) Thoracodorsal artery

iii) Subscapular artery

iv) Anterior circumflex humera artery and

v) Posterior circumflex humeral artery.

All these arteries had a normal course and relations. The third part of axillary artery had only one branch i.e. Anterior circumflex humeral artery. This artery wound around the humerus anteriorly and ended in intertubercular sulcus of humerus by dividing into ascending and descending branches without anastomosing with posterior circumflex humeral artery.

The posterior circumflex humeral artery, which was a continuation of the common trunk from the second part of axillary artery along with axillary nerve entered quadrangular space and wound around the humerus posteriorly, then it was divided into upper and lower branches deep to the deltoid muscle and ended by supplying shoulder joint and deltoid muscle.( Fig 1)

\section{Variation in forearm}

In the cubital fossa, the brachial artery divided into ulnar and radial arteries. The common interosseous artery originated from radial artery instead of ulnar artery. The ulnar artery was quite superficial. Instead of passing deep, it was superficial to pronator teres muscle and other flexor muscles of forearm under cover of deep fascia. Other branches followed normal pattern. (Fig 2)

\section{Variation in palm}

Superficial palmar arch was absent. The radial artery gave digital arteries for thumb and radial side of index finger. The ulnar artery continued medially giving digital arteries for little finger, ring finger, middle finger and ulnar side of index finger. (Fig 3)

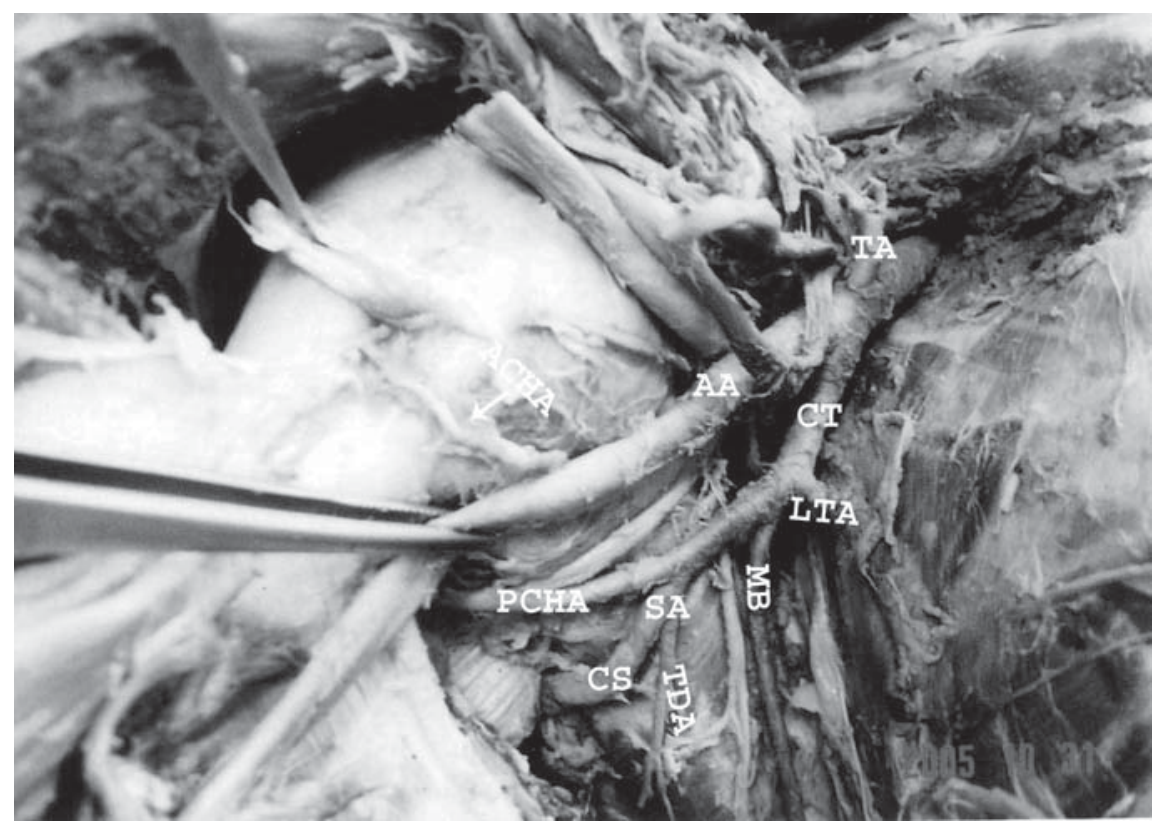

Fig 1: Variation of arterial system at axilla in right upper limb.

$\begin{array}{lll}\text { TA } & - & \text { Thoracoacromial artery } \\ \text { AA } & - & \text { Axillary artery } \\ \text { CT } & - & \text { Common trunk } \\ \text { LTA } & - & \text { Lateral thoracic artery } \\ \text { TDA } & - & \text { Thoracodorsal artery } \\ \text { ACHA } & - & \text { Anterior circumflex humeral artery } \\ \text { PCHA } & - & \text { Posterior circumflex humeral artery } \\ \text { SA } & - & \text { Subscapular artery } \\ \text { CS } & - & \text { Circumflex scapular artery } \\ \text { MB } & - & \text { Muscular branch }\end{array}$




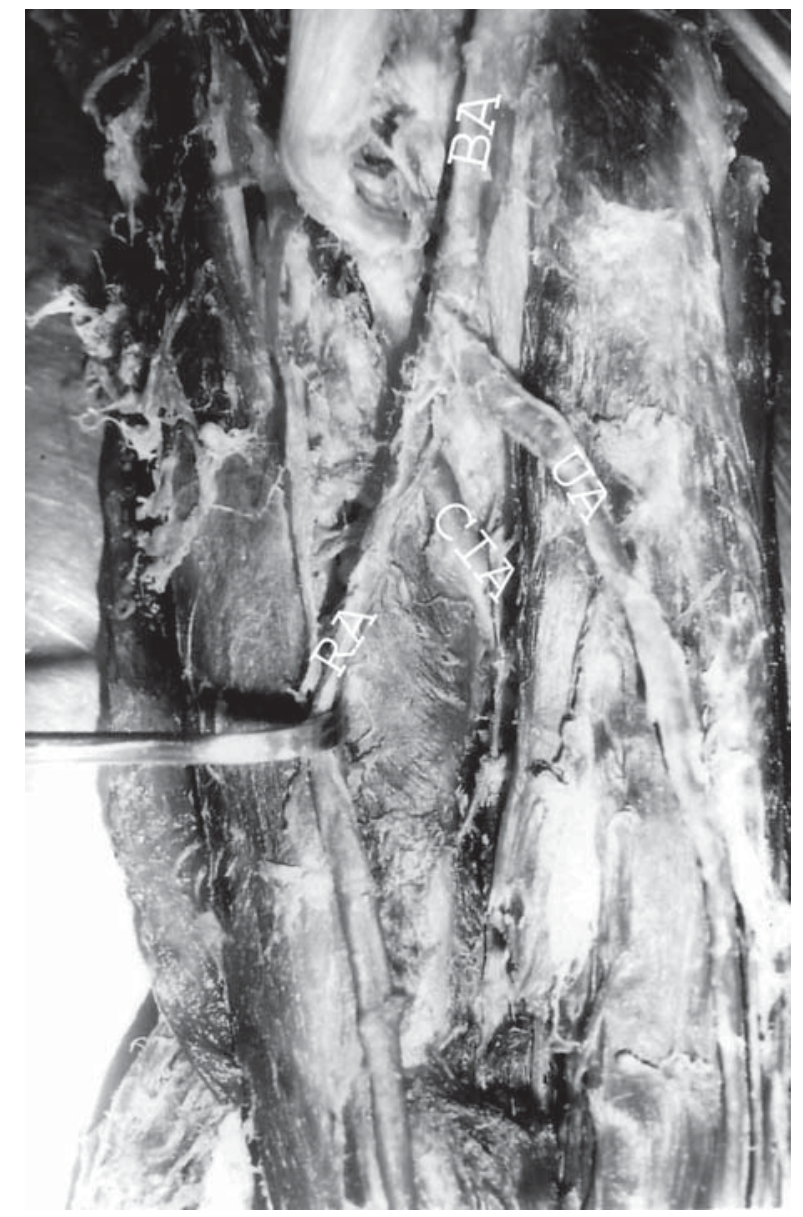

Fig 2: Variation of arterial system at forearm in right upper limb.

$\begin{array}{lll}\text { BA } & - & \text { Brachial artery } \\ \text { RA } & - & \text { Radial artery } \\ \text { UA } & - & \text { Ulnar artery } \\ \text { CIA } & - & \text { Common interosseous artery }\end{array}$

\section{Discussion}

Branches of axillary artery vary considerably. Occasionally subscapular artery, circumflex humeral artery and arteria profunda brachii arise in common ${ }^{1}$. But in our case lateral thoracic artery, thoracodorsal artery, subscapular artery, posterior circumflex scapular artery and posterior circumflex humeral artery only arise in common.

Venieratos D and Lolis ED reported another case in which subscapular artery, anterior and posterior circumflex humeral arteries, profunda brachii artery and ulnar collateral artery originated from a common trunk which was named by them as common subscapular trunk $^{2}$. Jurjus A et al reported a case in which radial and ulnar arteries were running superficial to flexor muscles of forearm ${ }^{3}$. Anil et al, Nakatani et al, Iyer Praveen

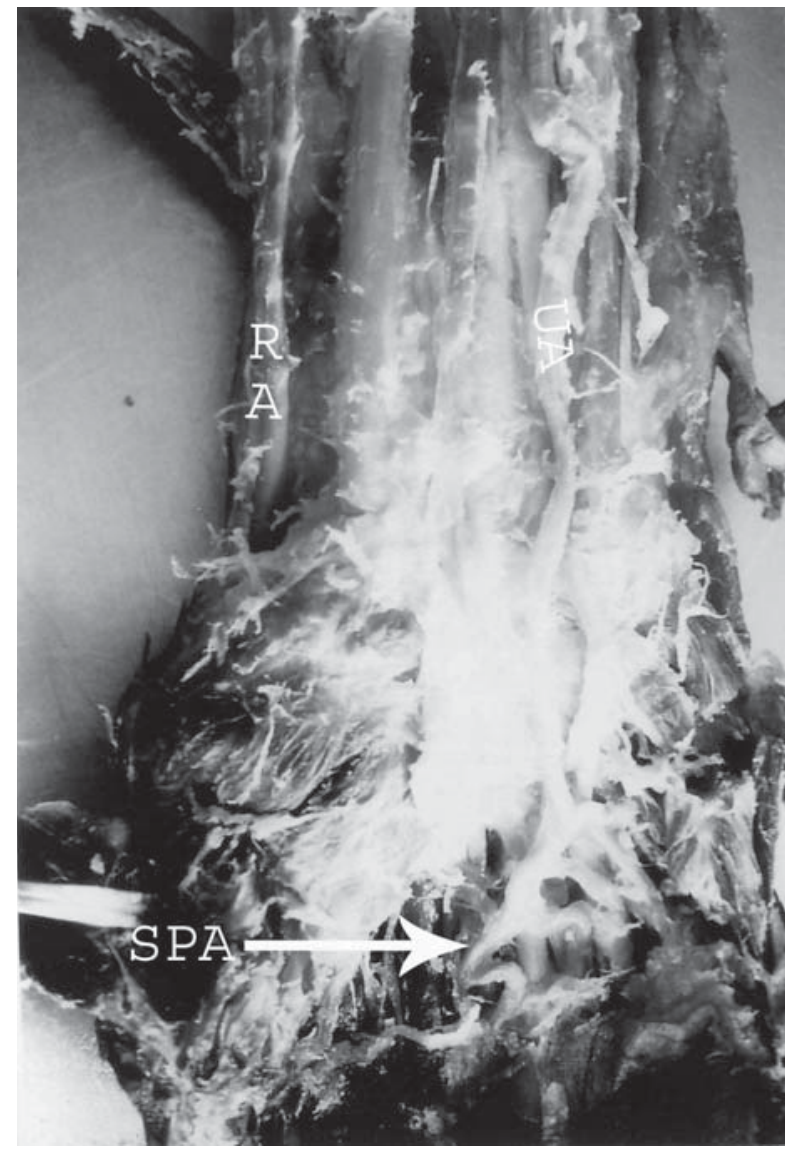

Fig 3: Variation of arterial system at palm in right upper limb.

$\begin{array}{lll}\text { UA } & - & \text { Ulnar artery } \\ \text { RA } & - & \text { Radial artery } \\ \text { SPA } & - & \text { Superficial palmar arch }\end{array}$

B, Weathersby H T, Yazar F et al, Fadel RA et al also reported superficial position of ulnar artery as in our observation $4^{5,6,7,8,9}$.

Mrudula et al found radial origin of common interosseous artery as our case ${ }^{10}$. B M Shenoy et al reported superficial radial and ulnar arteries wherein superficial radial artery gave origin to a common trunk which gave a median artery, muscular branches, artery replacing the anterior recurrent and common interosseous arteries ${ }^{11}$. But in our case only ulnar artery was superficial and common interosseous arteries was of radial origin.

Ajaya Udyavar observed the brachial artery dividing into radial and ulnar arteries with common interosseous artery arising from radial artery ${ }^{12}$. The ulnar artery 
was descending superficial to pronator teres muscles. Their findings accord with ours. U Anantha Kumari and Yousuf Begum also observed incomplete superficial palmar arch without any contribution from radial $\operatorname{artery}^{13}$.

The present case can be correlated embryologically.

Anomalies of blood vessels may be due to the:

- The persistence of vessels normally obliterated.

- The disappearance of vessels normally retained.

- Incomplete development.

- Fusions and absorption of the parts usually distinct.

- Choice of unusual paths in the primitive vascular plexuses $^{14}$

The development of artery of upper limb is as follows :

- originally the subclavian artery extends to the wrist where it terminates by dividing into terminal branches for the fingers. The distal portion of the artery becomes the interosseous artery of the adult.

- the median artery arises from the artery and get fused inferiorly with digital plexus while interosseous artery subsequently undergoes retrogression.

- The ulnar artery arises from brachial artery and unites distally with the median artery to form superficial palmar arch. Digital branches arise from this arch.

- The superficial brachial artery develops in the axillary region and traverses the medial surface of the arm and runs diagonally from the ulnar to the radial side of the forearm to the posterior surface of the forearm to the posterior surface of the wrist. Then it divides over the carpus into branches for the dorsum of the thumb and index finger.

Median artery retrogresses. The superficial brachial artery gives off a distal branch which anastomoses with superficial palmar plexus. At the elbow an anastomotic branch between brachial artery and superficial brachial artery becomes enlarged sufficiently to form radial artery as a major artery of the forearm. The proximal part of superficial brachial artery atrophies correspondingly ${ }^{15}$. In the present case it may happen that the proximal part of interosseous artery get anastomized with the radial artery and the part between the brachial artery and anterior interosseous artery retrogress. The communicating artery between anterior interosseous artery and radial artery form the common interosseous artery. The ulnar artery and radial artery may fail to communicate with superficial capillary plexus, so it retrogress and the superficial palmar arch fail to form.

\section{Conclusion}

Compta highlighted the diagnostic interventional and surgical significance of such a variation ${ }^{16}$. Unusual course and division of artery is important in surgical and angiographic procedures related to that region. Vascular anomalies occurring in common surgical sites tend to increase the likelihood of damage during surgery. Thus it is important for surgeons and radiologist. Superficial position of ulnar artery makes it vulnerable to trauma and thus to haemorrhage.

\section{References}

1. Bannister LH, Berry MM, Collins P, Dyson M, Dussek JE, Ferguson. Gray's Anatomy. 38th edition. Philadelphia: Churchill Livingstone; 1995.p. 1538- 44.

2. Venieratos D, Lolis ED. Abnormal ramification of the axillary artery: sub scapular common trunk. Morphologie. 2001; 85: 23-4.

3. Jurjus A, Sfeir R, Bezirdian R. Unusual variation of the arterial pattern of the human upper limb. Anat Rec. 1986; 215: 82-3.

4. Anil A, Turgut HB, Peber TV. A variation of the superficial ulnar artery. Surg Radiol Anat. 1996; 18: 237-40.

5. Nakatani T, Tanaka S, Mizubami S et al. The superficial ulnar artery originating from the axillary artery. Anat Anz. 1996; 178: 277-9.

6. Iyer Praveen B. Superficial ulnar artery - a case report. J Anat. Soc. 2005; 54: 48.

7. Weathersby HT. Unusual variation of the ulnar artery. Anat Rec. 1956; 124: 245-8.

8. Yazar F, Kirici Y, Ozan H.An unusual variation of the superficial ulnar artery. Surg Radiol Anat. 1999; 21: 155-7.

9. Fadel RA, Amonov-Kuofi HS. The superficial ulnar artery: development and surgical significance. Clin Anat. 1996; 9: 128-32.

10. Mrudula S, Bindu NH. Radial origin of common interosseous artery- a case report. J Anat. Soc, 2005; 54: 50.

11. Shenoy BM, D'Costa S, Narayana K. A case of variation of arterial pattern of the upper limb. J Anat. Soc. 2004; 53:41.

12. Udyavar A. Anomalous termination of the brachial artery. J Anat. Soc. 2004; 53:41.

13. Anantha UK, Begum Y. Incomplete superficial palmar arch without contribution from radial artery. J Anat. Soc. 2003; 52:99. 
14. Arey LB. Development Anatomy in: Development of the arteries, 6th edition. Philadelphia : WB Saunders Co; 1957.p. 37577.

15. Larsen WJ, Sherman LS, Potter SS, Scott WJ. Human embryology. 3rd edition. Philadelphia: Churchill Livingstone; 2001.p. 207.
16. Gonzalez- Compta X. Origin of radial artery from axillary artery and associated hand vascular anomalies. J Hand Surg (Am). 1991; 16:293-6. 